\title{
Reducing the Cooling Energy of Existing Commercial Buildings with Passive Thermal Mass
}

\author{
Phillip Roach*
}

\author{
Barbara Handy Institute, University of South Australia, Mawson Lakes Boulevard, Mawson Lakes, S. A. 5095, \\ Australia
}

\begin{abstract}
A major part of sustainability theory and practice is to reuse existing building stock wherever possible and to refrain from demolition and rebuilding minimising the resources and associated energy used. Many buildings therefore have internal refurbishments during their lives, the scale of which can range from minor fit outs through major interior refurbishments to finally those which see the central services replaced also.

The ability to greatly improve the efficiency of a building during only minor refurbishment is an attractive proposal which would provide an intermediate opportunity to building owners to reduce cooling energy and its associated cost and more importantly avoid disruption to the base building services.
\end{abstract}

This study investigates the effect of exploiting inherent building thermal mass in a standard commercial building in the Australian cities of Adelaide and Brisbane, and demonstrates the energy savings that can be made in the order of $30 \%$.

Keywords: Night cooling, facades, low energy, passive thermal mass.

\section{INTRODUCTION}

The benefits of thermal mass when used in conjunction with night time cooling as a strategy for reducing energy in commercial buildings $[1,2]$ is well researched. Thermal mass has the ability of absorbing the high levels of internal heat gains experienced in commercial buildings [3]. However, with architectural trends leading to the construction of more fully glazed buildings, the addition of thermal mass to existing buildings, presents a practical challenge. Many of these commercial buildings include suspended ceilings and floor coverings. Retrofit of buildings offers a unique opportunity to enhance the energy efficiency of the building. Stripping of internal fabric coverings exposes the building to internal thermal mass and therefore offers a low cost solution to reducing cooling energy [4]. Identified the benefits of removing carpets and exposing the concrete floors. There is limited research into the impact of exposed floors and ceilings in commercial buildings with glazed facades. This study uses Energy Plus to investigate the potential energy savings of this retrofit measure. The study covers the range of climates from arid to humid, as found in Australian climate zones of Adelaide (Warm Marine) and Brisbane (Mixed Humid).

\section{BUILDING AND PLANT MODEL}

The Australian climate during summer differs greatly between hot arid conditions in Adelaide to warm humid

*Address correspondence to this author at the Barbara Handy Institute, University of South Australia, Mawson Lakes Boulevard, Mawson Lakes, 5095

S. A., South Australia; Tel: 00614969 6037;

E-mail: phillip.roach@mymail.unisa.edu.au conditions in Brisbane, but both, as in other parts of the world, of these two major Australian cities use identical construction techniques for buildings. Past research implies that humid locations offer a lower opportunity for diurnal cooling techniques over dry climates [3]. Research has also demonstrated that whilst cooling energy use may be reduced by the exploitation of thermal mass, peak plant loads may increase [6] and therefore an increase in thermal mass may be unacceptable as a retrofit measure for existing plant. Whilst thermal mass has been demonstrated to provide financial savings from its exploitation [7], the challenge of this study is to demonstrate that total heating and cooling energy can be reduced by exposing thermal mass in existing buildings.

Previous research has demonstrated that operating an economiser cycle in night ventilation mode can reduce energy consumption for air conditioning a building [8], making use of storing cooling in the thermal mass.

The different styles of conditioning systems used worldwide can be summarised into two primary groups. They are centralised systems (Variable Air Volume, Constant Air Volume, and Dual Duct) or decentralised systems (Fan Coil Units, Variable Refrigerant Volume, Direct Expansion Split Conditioners, and Chilled Beams). The differentiating factor is the manner in which outside air is supplied to the occupied zones and the ability for each of the systems to modulate the proportion of outside air supplied at any time during operation. This research applied a centralised, variable air volume air conditioning system. Centralised 
systems have the ability, using economiser cycles, to supply $100 \%$ outdoor air into the occupied spaces when ambient conditions are favourable and therefore can offer a great potential for the exploitation of thermal mass within the building to reduce energy consumption, plant size and peak demand.

Shifting energy use to 'off peak' periods is a key design strategy to maximise lower cost energy Decentralised systems are usually designed for a fixed proportion of outdoor air independent of indoor conditioning units. Therefore the possibility exists for the outdoor air supply to be operated independently of the room conditioners during economiser or night cycle periods. To fully maximise the outdoor capacity of this style of system, an investigation would be required into the ability of the base system to accommodate an increased volume of outdoor air, particularly for night time purging of the thermal mass. This would be dependent on the original design basis and would be different for every system. The differing basis for selecting the outdoor air volume is also a factor to be considered with many buildings delivering an increased volume to benefit the indoor environmental air quality [9]. It is critical that the outside air system can operate independently of the active cooling system otherwise active cooling would be operating unnecessarily for decentralised systems.

Many buildings however, do not have the capability of operating in economiser mode and only minimal quantities of outside air are provided to internal spaces. The Building Code of Australia only mandates the use

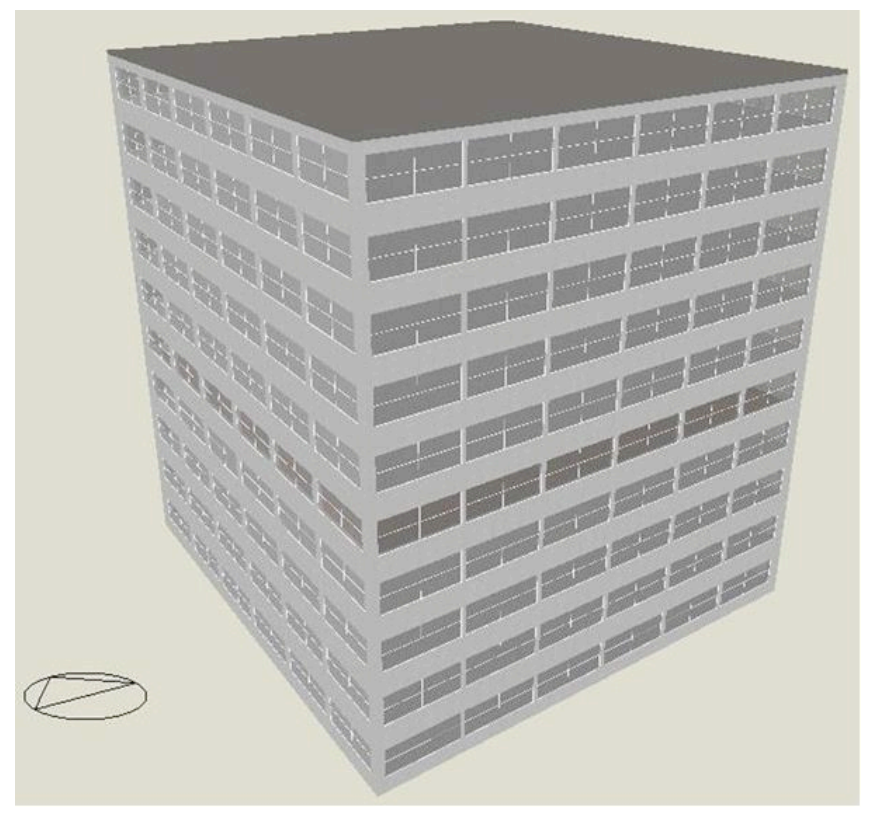

Figure 1: Building model image. of economiser cycle systems for a plant or system over a specific duty [10], but considering most buildings comprise a number of smaller systems, this requirements appears flawed.

To analyse the effect of exploiting the inherent thermal mass, a building model was developed using Energy Plus and extensive simulations were carried out, with data interpreted via the Design Builder Software. A standard building footprint of $32 \times 32 \mathrm{~m}$ (105ft $\times 105 \mathrm{ft})$, with over 10 floors is recommended by the Australian Buildings Controls Board [11] as being a typical built form for major Australian cities (Figure 1).

Since it has been previously demonstrated that above a glazed opening percentage of $60 \%$ no benefit in respect of day lighting energy is made [12], $60 \%$ is used as the glazing percentage for the building. The mid height, fourth floor was simulated for annual cooling energy with a room set point of $25^{\circ} \mathrm{C}\left(77^{\circ} \mathrm{F}\right)$ and standard operating hours of $7 \mathrm{am}$ to $7 \mathrm{pm}$ and internal gains of $25 \mathrm{~W} / \mathrm{m}^{2}\left(7.92 \mathrm{Btu} / \mathrm{h} \mathrm{ft}{ }^{2}\right)$ for the occupied period of $8 \mathrm{am}$ to $6 \mathrm{pm}$. Whilst the effect of internal gains has been demonstrated to affect the selection of optimum structures [13, 14], the $25 \mathrm{~W} / \mathrm{m}^{2}$ $\left(7.92 \mathrm{Btu} / \mathrm{h} \mathrm{ft}^{2}\right.$ ) was selected as a typical operational figure which is not intended to be a dominant factor in this analysis.

The outdoor air supply to the building was operated on a thermostatic strategy, with the required minimum of $10 \mathrm{~L} / \mathrm{s} / \mathrm{p}(21.2 \mathrm{cfm} / \mathrm{p})$ per person (with an occupation density of $1 \mathrm{p} / 10 \mathrm{~m}^{2}\left(1 \mathrm{p} / 107.6 \mathrm{ft}^{2}\right)$ being available from $8 \mathrm{am}$ to $6 \mathrm{pm}$ and an increased amount of $12 \mathrm{ach} / \mathrm{hr}$, for centralised systems, being available when the ambient temperature was below $15^{\circ} \mathrm{C}\left(59^{\circ} \mathrm{F}\right)$. The decentralised systems were modelled in a similar way but with a fixed outdoor air volume, ranging from $10 \mathrm{~L} / \mathrm{s}$ to $20 \mathrm{~L} / \mathrm{s}$ (21.2cfm to $42.2 \mathrm{cfm}$ ) per person. The reasoning behind this is that these simpler decentralised systems would not normally have sophisticated controls to modulate the outside air percentage unless a full economiser cycle was integrated.

To highlight the changes in energy use from exposing internal thermal mass, the energy used in fan power has been ignored in all cases but an estimation of the effect the inevitable power use is made at the end of the report. The impact of this would be greater for centralised systems than decentralised and may be in the order of $15 \%$ of the cooling energy during summer conditions [15]. Research is being undertaken however, to reduce the energy used by fans during 
economiser cycles and a reduction in the order of $30 \%$ is possible [16]. Because of the great number of variables in fan power and the opportunity in some buildings for natural ventilation, it is excluded from this assessment.

A composite façade wall structure was analysed against a changing quality and distribution of internal thermal mass. The effect of additional internal mass was also investigated as a parameter, which could be

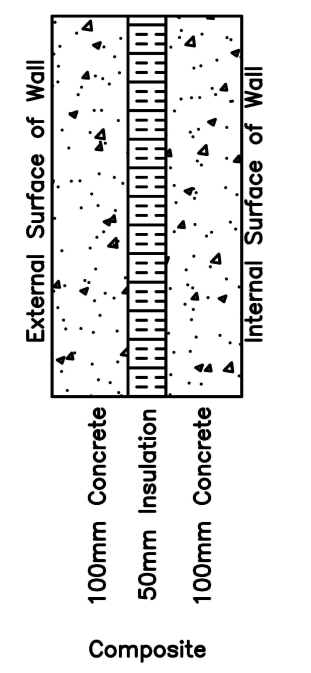

Figure 2: Cross sections of the wall structure investigated. represented by the construction of heavyweight internal walls. The composite structure was selected since it has been demonstrated to operate as an optimum façade in both the climates of Adelaide and Brisbane [8]. The wall structure is identified in Figure 2 with the thermodynamic properties of the wall scheduled in Table 1.

The composite wall also demonstrates the ability of the façade to absorb heat gains, both internally and externally without affecting greatly the accessible thermal mass [17-19].

\section{ANALYSIS OF BASE CASE FOR A CENTRALISED SYSTEM}

A composite wall construction of $100 \mathrm{~mm}$ (4in.) concrete, $50 \mathrm{~mm}$ (2in.) polystyrene insulation with a further leaf of $100 \mathrm{~mm}$ (4in.) concrete was initially used as a base façade with internal scenarios as follows:

- $10 \mathrm{~mm}$ (0.4in.) ceiling structure and $7 \mathrm{~mm}$ (0.27in.) floor covering.

- $\quad$ No ceiling structure and $7 \mathrm{~mm}$ (0.27in.) floor covering.

- $\quad 10 \mathrm{~mm}$ ceiling structure and no floor covering.

- No ceiling structure and no floor covering.

Table 1: Summary of Properties of the Wall Structure Investigated

\begin{tabular}{|c|c|c|c|c|c|}
\hline & $\mathbf{U}\left(\mathbf{W} / \mathbf{m}^{2} \mathbf{K}\right)$ & $\mathbf{R}\left(\mathbf{m}^{2} \mathbf{K} / \mathbf{W}\right)$ & Total Mass $\left(\mathbf{k g} / \mathbf{m}^{2}\right)$ & Thickness $(\mathbf{m m})$ & Accessible Internal Mass $\left(\mathrm{kg} / \mathrm{m}^{2}\right)$ \\
\hline \hline Composite Wall & 0.64 & 1.563 & 420.8 & 250 & 210 \\
\hline
\end{tabular}

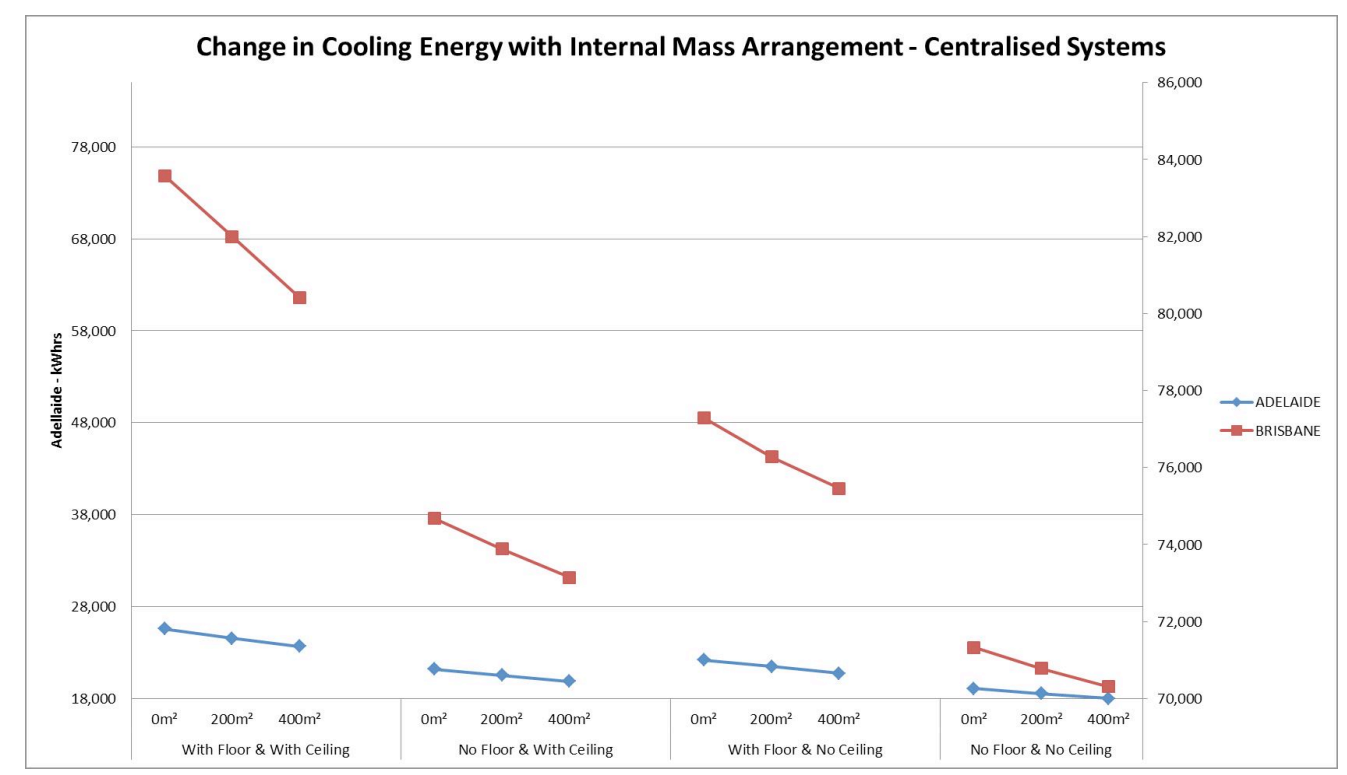

Figure 3: Annual Cooling Thermal Energy with varying internal thermal mass for centralised systems. 
Each of these ceiling and floor scenarios were combined with a proportion of internal wall thermal mass being exposed as follows:

- $\quad 0 \mathrm{~m}^{2}, 200 \mathrm{~m}^{2}$ and $400 \mathrm{~m}^{2}\left(0 \mathrm{ft}^{2}, 2152.8 \mathrm{ft}^{2}\right.$ and $\left.4305.6 \mathrm{ft}^{2}\right)$ internal wall mass exposed $(200 \mathrm{~mm}$ (8in.) concrete) - This can be viewed as existing mass having coverings removed or the addition of new heavyweight components in lieu of lightweight partitions.

- The minimum level of thermal mass was therefore $10 \mathrm{~mm}(0.4 \mathrm{in}$.) ceiling structure, $7 \mathrm{~mm}$ (0.27in.) floor covering and $0 \mathrm{~m}^{2}\left(\mathrm{Oft}^{2)}\right.$ internal walls mass exposed and the maximum level of thermal mass was for no ceiling structure, no floor covering and $400 \mathrm{~m}^{2}\left(4305.6 \mathrm{ft}^{2}\right)$ internal wall mass exposed.

- It would be typical for buildings to include a floor covering and suspended ceiling and this should be considered the base case.

Figure 3 and 4 present the total annual cooling energy demand from the building subject to different exposed surfaces. For all cases, increasing the exposed internal thermal mass delivered energy savings for cooling. For the case of no exposed internal thermal mass, exposing the floor and ceiling delivered a $25 \%$ and $15 \%$ for Adelaide and Brisbane, respectively. With only the floor exposed a saving of $17 \%$ and $10 \%$ was achieved for Adelaide and
Brisbane, respectively. With only the ceiling exposed, a $13 \%$ and $8 \%$ saving was achieved for Adelaide and Brisbane, respectively. Intuitively, an exposed ceiling would be expected to deliver greater savings than an exposed floor due to increased natural convection effects. Upon closer inspection of the data it was found that exposing the floor yielded greater annual energy savings and that exposing areas of internal thermal mass (walls) increased savings further. Overall, a case can be made that exposing floors and ceilings to the internal space offers meaningful energy savings for existing buildings. Exposing internal mass in the form of walls is demonstrated as having a limited effect compared to the floor and ceilings. Savings of $7.5 \%$ and $3.8 \%$ for Adelaide and Brisbane respectively are achieved for the base case of floors and ceilings covered.

\section{ANALYSIS OF BASE CASE FOR A DECENTRALISED SYSTEM}

Centralised systems have an advantage over decentralised systems in that they generally have access to higher volumes of outdoor air. Operation of these systems would integrate outside air modulation control which would supply only the minimum required volume of outside air should ambient conditions not be desirable for economiser cooling. In decentralised system outside air is supplied at a fixed volumetric flow rate and operated either during occupancy or as part of a night ventilation strategy by the use of a differential (ambient to inside) thermostat. In a similar method to

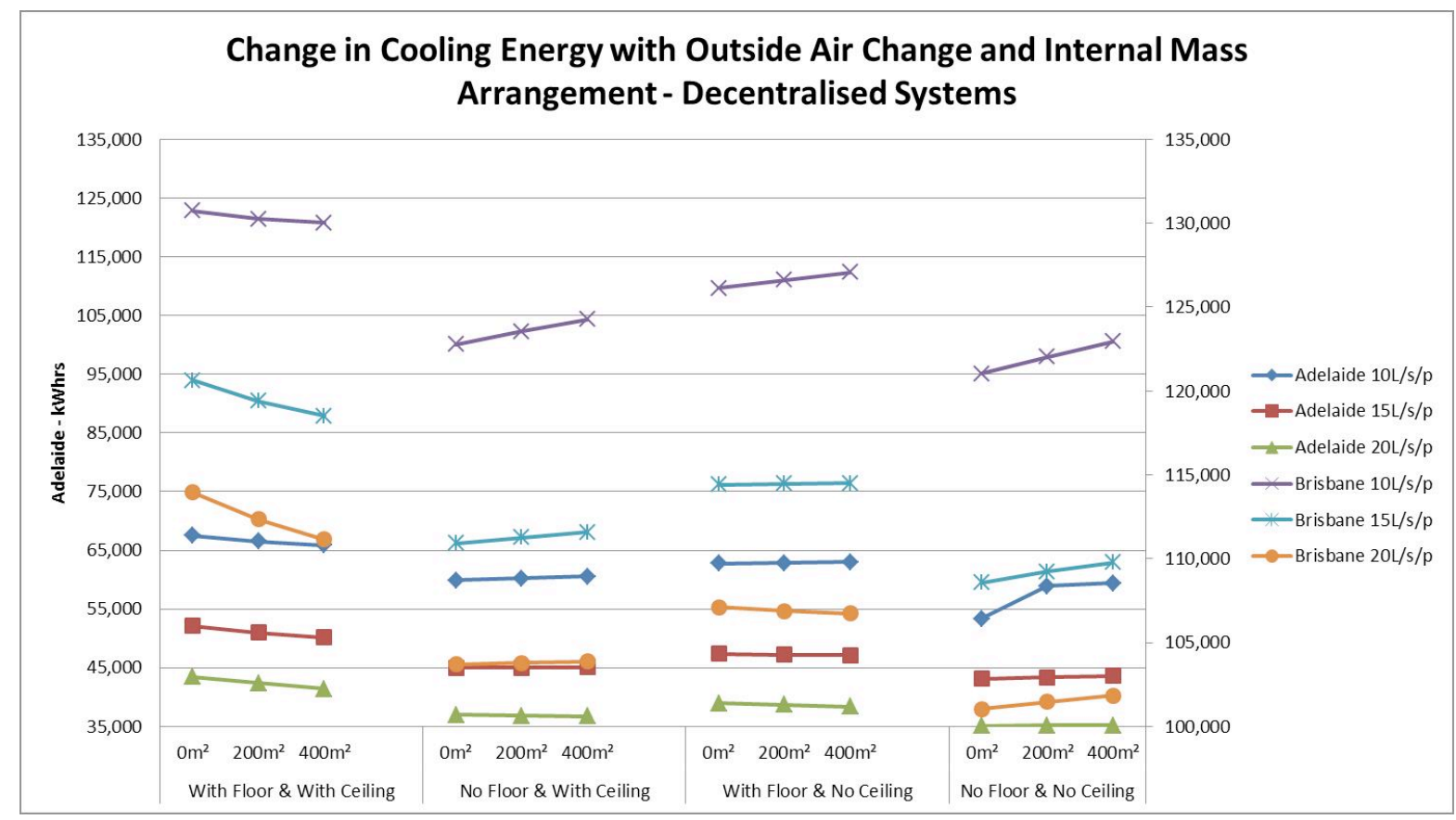

Figure 4: Annual cooling energy for differing facades for decentralised systems (kWhrs). 
that undertaken for centralised systems, the annual cooling energy for decentralised systems was simulated for Adelaide and Brisbane.

Using the $15 \mathrm{~L} / \mathrm{s} / \mathrm{p}(31.8 \mathrm{cfm} / \mathrm{p})$ outside air flow rate for comparison, removing the floor and ceiling coverings yielded a reduction in energy of $17 \%$ and $10 \%$ for Adelaide and Brisbane, respectively. Removing the floor covering alone resulted in a $14 \%$ and $8 \%$ decrease and for ceiling coverings $10 \%$ and $5 \%$ for Adelaide and Brisbane, respectively. This correlates well with the earlier findings for a centralised system in that the floor offers greater potentials for energy reduction by the exposing of its thermal mass. When additional internal mass is exposed however, an increase in energy is observed and this is more pronounced for the lower outdoor flow rates of 10 and $15 \mathrm{~L} / \mathrm{s}(21.2$ and $31.8 \mathrm{cfm})$. This implies that the limit of benefit for these lower volumes of outside air which was not a limitation in the centralised plant option.

The change of transferring from minimal thermal mass (ceilings and floors covered with $0 \mathrm{~m}^{2}\left(\mathrm{Oft}^{2}\right)$ internal mass) to maximum thermal mass (ceilings and floors exposed with $400 \mathrm{~m}^{2}\left(\mathrm{Oft}^{2}\right)$ internal mass) reduces the annual cooling energy in Adelaide and Brisbane by $20 \%$ and $13 \%$ respectively. This is a substantial difference, which can be accommodated into most systems with the required modifications to the built form and services.
As with the centralised system previously, the effect of increasing the quantity of internal mass in the form of walls is limited. It can also be noticed that as the overall exposed thermal mass area increases when floors and ceilings are already exposed, annual energy increases and the theoretical limit of mass for a $10 \mathrm{~L} / \mathrm{s} / \mathrm{p}$ $(21.2 \mathrm{cfm} / \mathrm{p})$ is identified. With the limitation on outside air flow rates experienced by these decentralised systems, the exposing of additional internal thermal mass was counterproductive.

\section{EFFECT OF VARYING THE QUANTITY OF AVAILABLE OUTSIDE AIR FOR FIXED INTERNAL THERMAL MASS}

To investigate how the quantity of the outside air volume affected the annual cooling energy consumption, additional simulations were undertaken for both centralised and decentralised systems.

Initially, for centralised systems, the maximum volume of outside air was changed on an ach/hr basis, and the same control strategy applied. The minimum volume was still retained at $10 \mathrm{~L} / \mathrm{s} / \mathrm{p}(21.2 \mathrm{cfm} / \mathrm{p})$, which, for this particular building equals $1 \mathrm{ach} / \mathrm{hr}$ due to the floor plate area and occupation density.

Table 4 / Figure 5 clearly demonstrate that increasing the outdoor air flow rate offers savings in the annual cooling energy of the building. From $1 \mathrm{ach} / \mathrm{hr}$ to $6 \mathrm{ach} / \mathrm{hr}$, the saving is $70 \%$ and $43 \%$ for Adelaide and

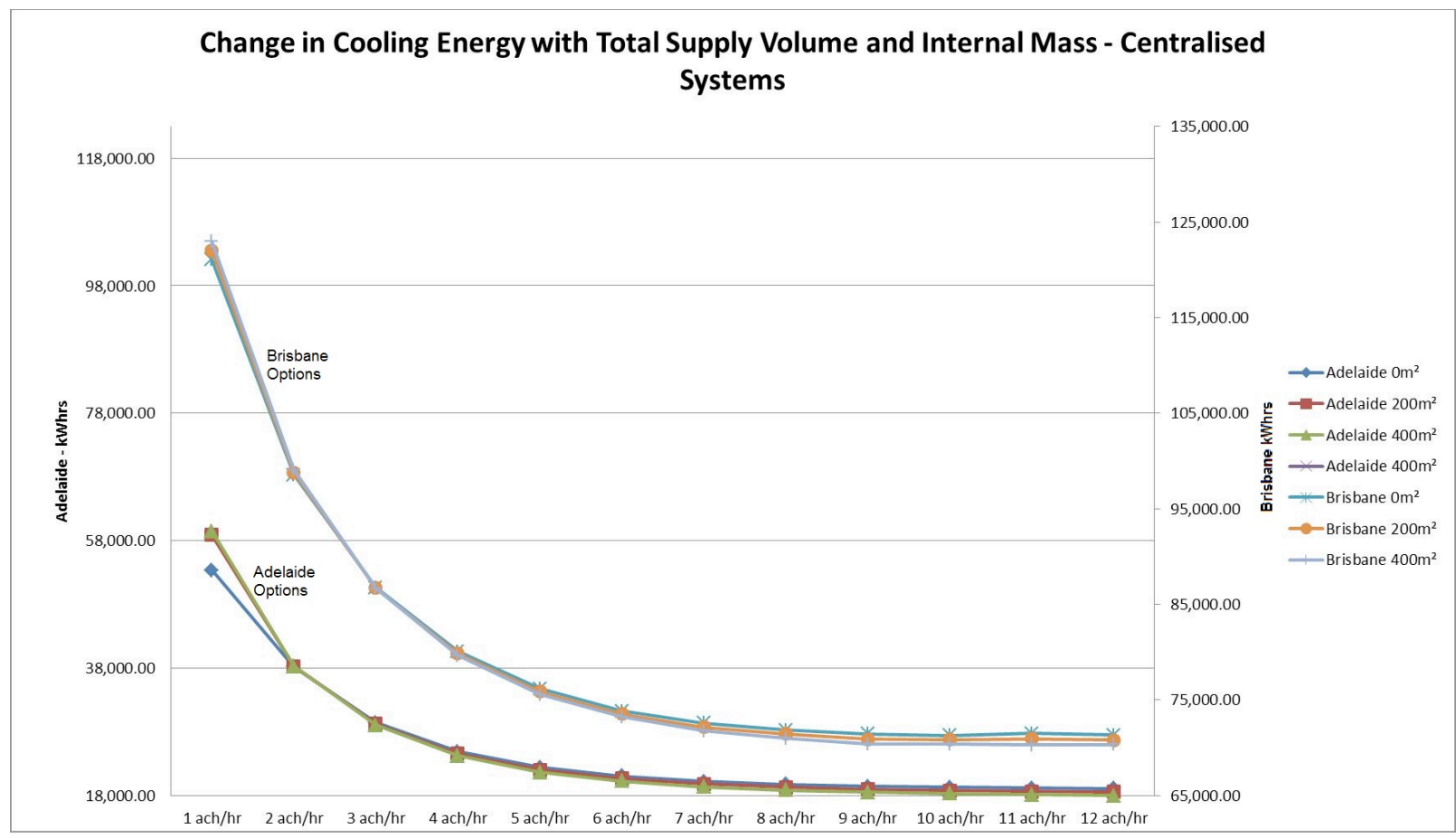

Figure 5: Annual cooling energy for differing outdoor air flows for centralised systems. 
Brisbane, respectively. The impact of increased internal thermal mass was negligible.

A similar analysis was undertaken for decentralised systems, but unlike in the earlier section, the outdoor air flow rate was varied in the range from $10 \mathrm{~L} / \mathrm{s} / \mathrm{p}$ $(21.2 \mathrm{cfm} / \mathrm{p})$ through to $70 \mathrm{~L} / \mathrm{s} / \mathrm{p}(148.3 \mathrm{cfm} / \mathrm{p})$. As before, there are no controls to modulate this level of outside air and it is on during occupied periods and controlled thermostatically out of hours (Figure 6).

It can be seen that there is a clear benefit to be gained from increasing the outdoor air flow rate up to $40 \mathrm{~L} / \mathrm{s} / \mathrm{p}$ (84.8cfm/p), after which, the energy levels begin to increase again. This increase is due to the system not being able to limit the outdoor air volume when ambient conditions were not suitable. If this limit was in place the graph would be similar to that of the centralised system.
Naturally, the outdoor air system must be able to accommodate the additional air flow to attain the higher levels of savings, but an increase from $10 \mathrm{~L} / \mathrm{s}$ to $20 \mathrm{~L} / \mathrm{s}$ (21.2 to $42.4 \mathrm{cfm}$ ) could be accommodated by replacement of a central fan and some local acoustic treatment. The savings at $40 \mathrm{~L} / \mathrm{s} / \mathrm{p}(84.8 \mathrm{cfm} / \mathrm{p})$ of $64 \%$ and $24 \%$ for Adelaide and Brisbane, respectively, demonstrate the positive effect that exploitation of the internal thermal mass has on the cooling energy use within the building. The reduced percentage savings seen for Brisbane reflect the penalty associated with the high latent load of the outside air in this location.

\section{QUANTIFYING THE EFFECT OF OUTDOOR FLOW RATE AND THERMAL MASS ON PLANT SIZE}

With the outdoor air system volume being increased for all operating periods, an increase in peak cooling

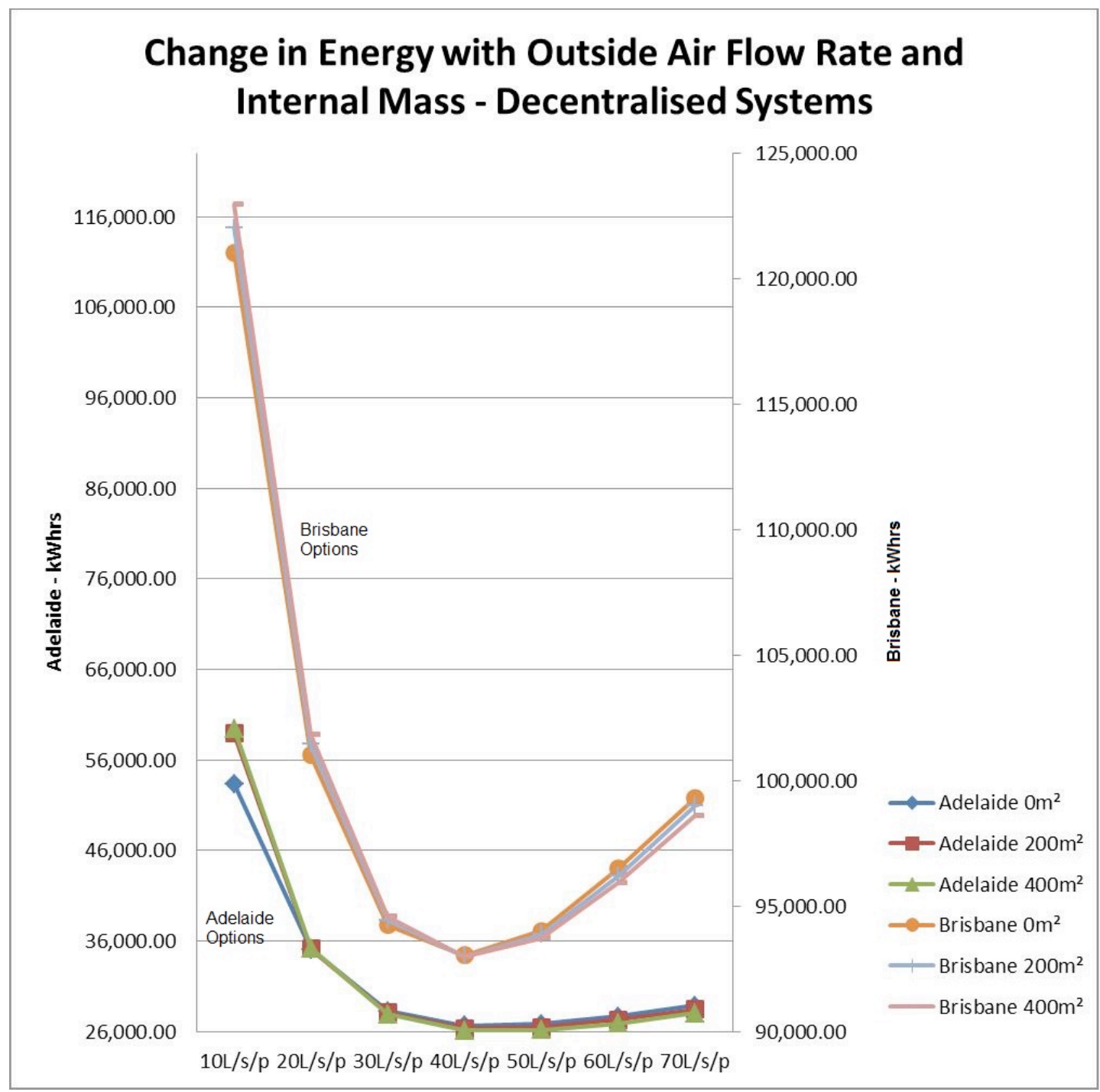

Figure 6: Changing the outside air volume on decentralised systems. 


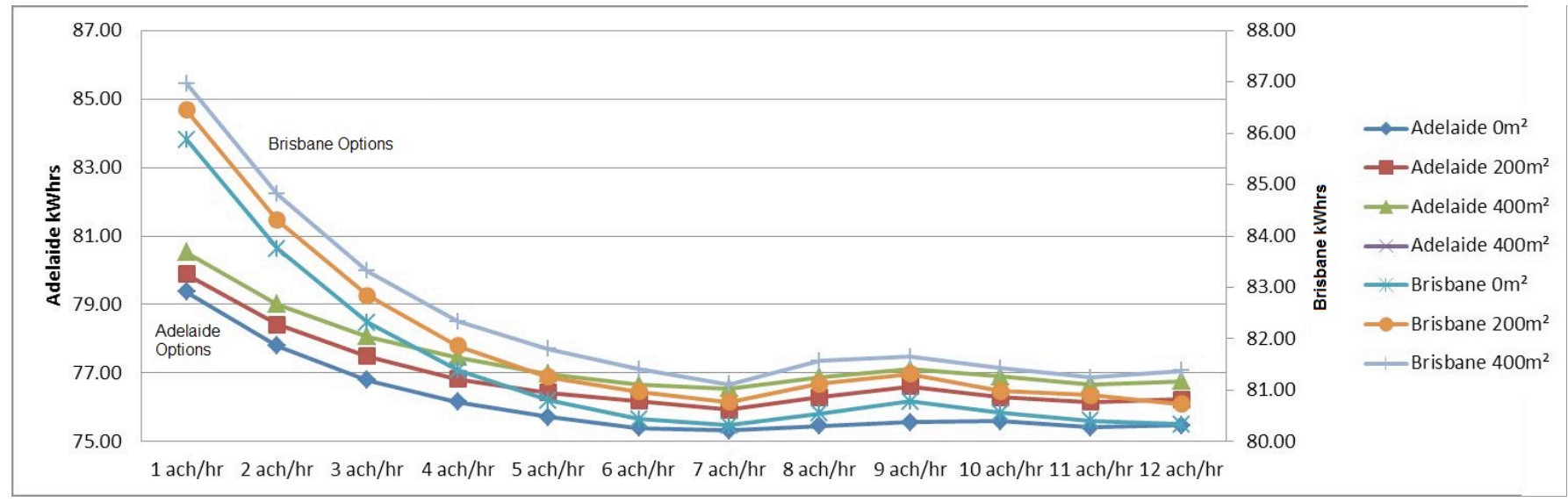

Figure 7: Effect of thermal mass and outside air rate on centralised system plant capacity.

loads is expected. With the ceilings and floor coverings again removed, the peak cooling load for a range of outdoor air flow rates was calculated for Adelaide and Brisbane (Figure 7).

The changes had a demonstrated effect on the peak cooling for the centralised system with the range between maximum and minimum for each location only varying by around $7 \%$. It can be seen though, that the availability of free cooling from outside air has an impact on overall plant size, but this is limited in effect after 6 ach/hr.

The increase in internal thermal mass from $0 \mathrm{~m}^{2}$ to $400 \mathrm{~m}^{2}\left(0 \mathrm{ft}^{2}\right.$ to $\left.4305.6 \mathrm{ft}^{2}\right)$ consistently reduces the peak load by around $1.5 \%$ in each location.

Increases in peak cooling loads for Adelaide and Brisbane, for decentralised systems, are proportional to the quantity of additional outside airflow. Brisbane being higher due to the additional latent loads placed on the plant by the higher ambient humidity levels. If these systems had more advanced controls which permitted the modulation of outside air when the outside air volume increases, there would not be such a great increase in plant capacity, as seen with the centralised system (Figure 8).

\section{EXAMINING THE EFFECT OF EXPOSING INTERNAL THERMAL MASS IN LIGHTWEIGHT BUILDINGS}

It is very likely that an existing building does not have a composite façade matching the exact requirements of the model simulated in this paper. Indeed, there has been a trend in recent years to fully glazed buildings with no façade thermal mass and these buildings equally ignore the opportunities for savings afforded by the exploitation of internal thermal mass.

Providing mass composite facades for the building's construction will reduce the benefits of exposing slab.

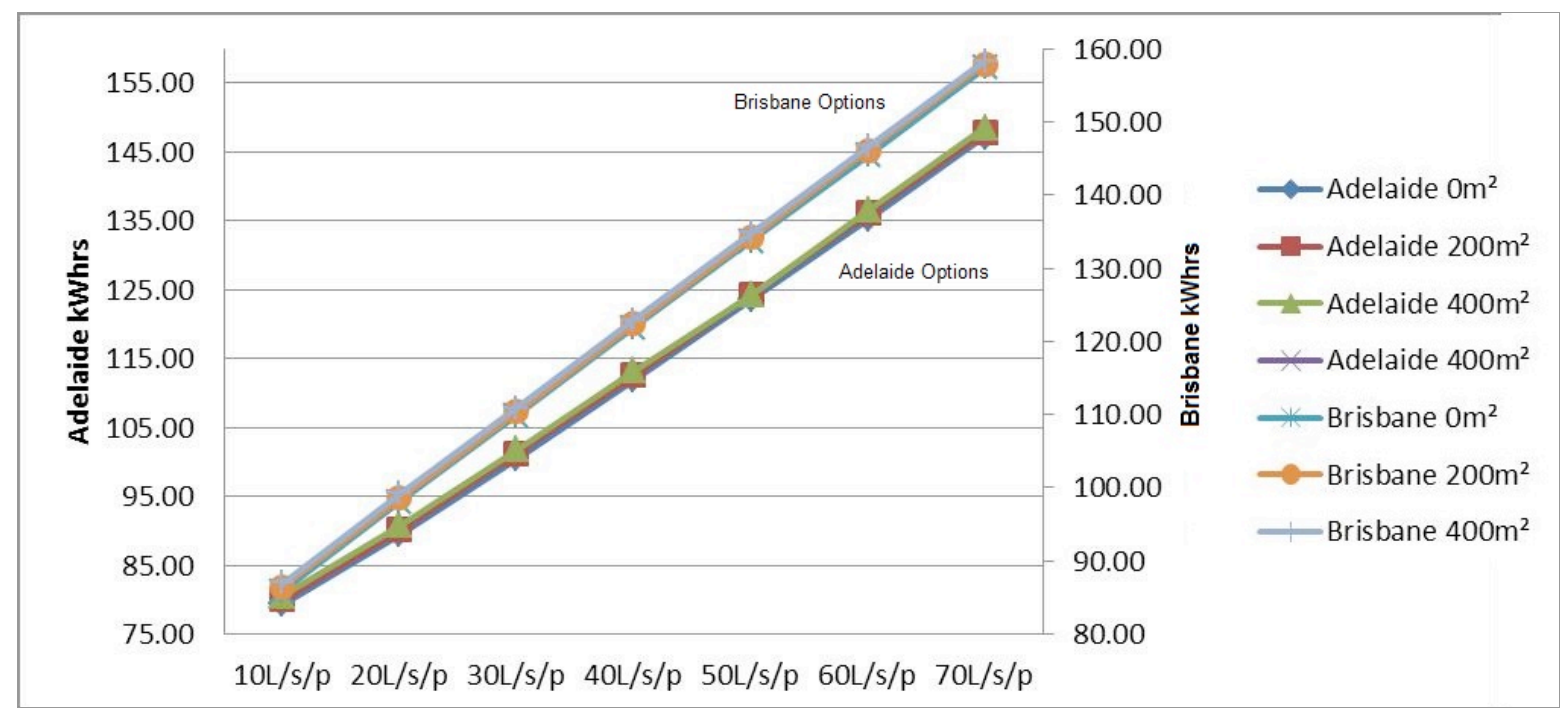

Figure 8: Effect of thermal mass and outside air rate on decentralised system plant capacity. 
Therefore for less mass facades the savings will be greater. To illustrate this, a building with the same dimensions as the one previously simulated was analysed, with a curtain walling façade of $100 \%$ glazing, utilising double glazing with a generic $3 \mathrm{~mm}$ (0.12 in.), green tinted, outer leaf, a $13 \mathrm{~mm}$ (0.51 in.) argon fill and $3 \mathrm{~mm}$ (0.12 in.) clear inner leaf. The glazing had a resulting solar heat gain coefficient of 0.616 and a thermal transmittance of $2.556 \mathrm{~W} / \mathrm{m}^{2} \mathrm{~K}$ (0.404 Btu/( $\left.{ }^{\circ} \mathrm{F} \mathrm{ft}^{2}\right)$ (Figure 9).
As before, simulations were undertaken for a fully ducted system, capable of economiser operation with a volumetric flow of $12 \mathrm{ach} / \mathrm{hr}$ and a split ducted system with an outside air provision of $10 \mathrm{~L} / \mathrm{s} / \mathrm{p}(21.2 \mathrm{cfm} / \mathrm{p})$. Simulations were carried out for Adelaide and Brisbane conditions with the results demonstrated below (Figures 10, 11):

As with the composite façade building, it can be seen that the exploitation of internal thermal mass

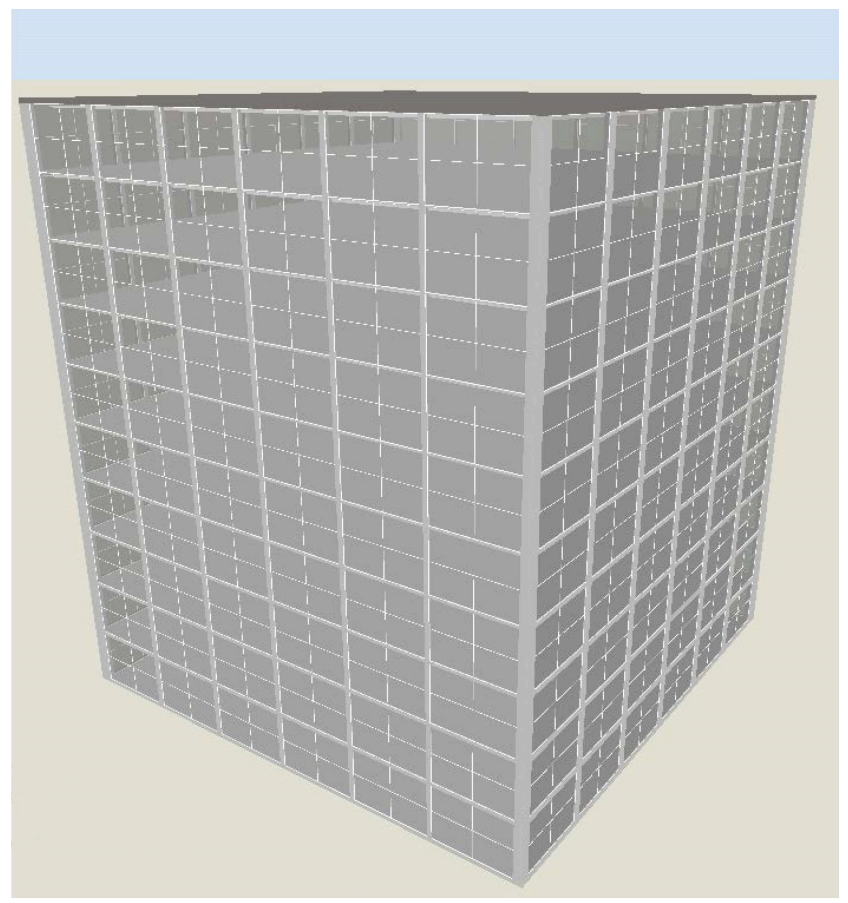

Figure 9: Model of fully glazed, lightweight façade building.

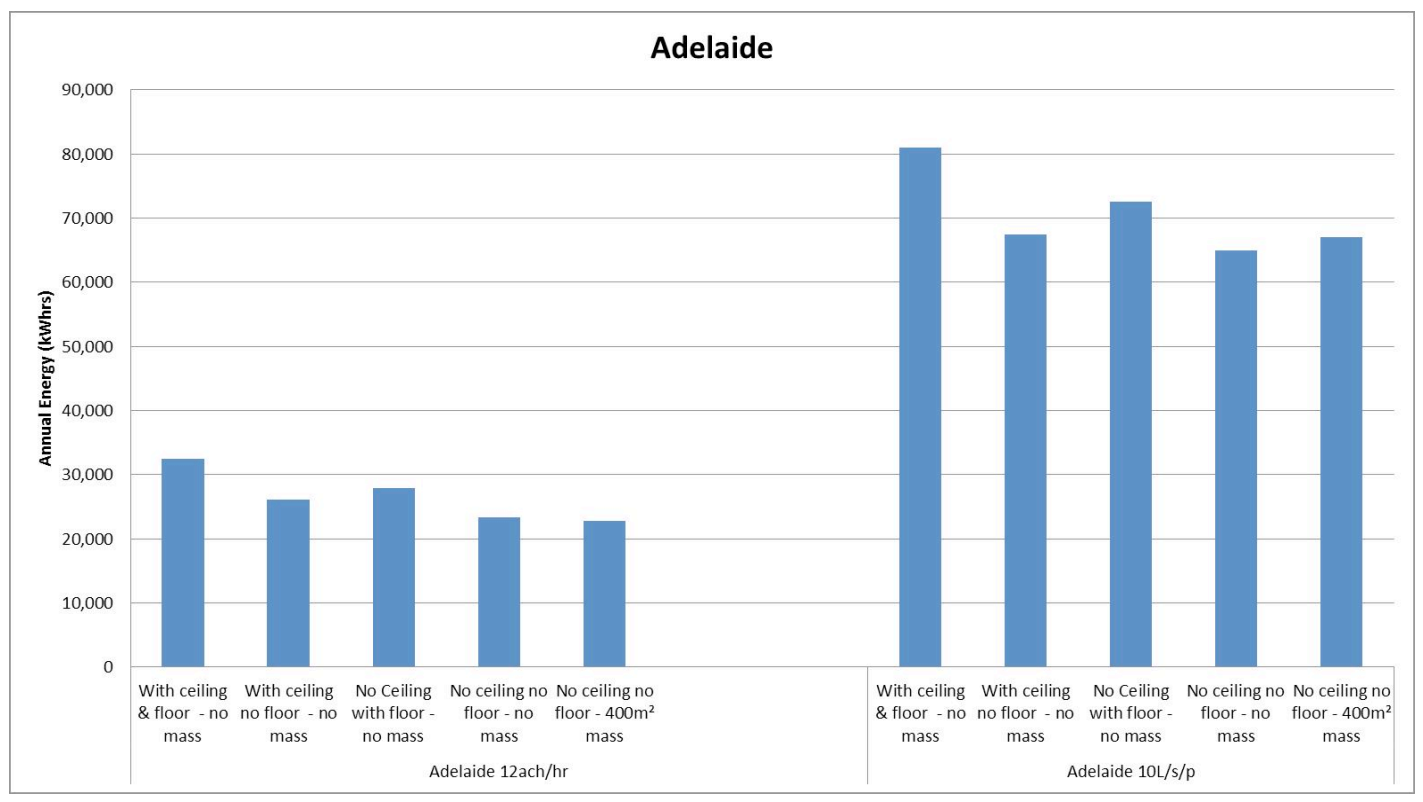

Figure 10: Effect of exposing internal thermal mass on annual energy use (Adelaide). 


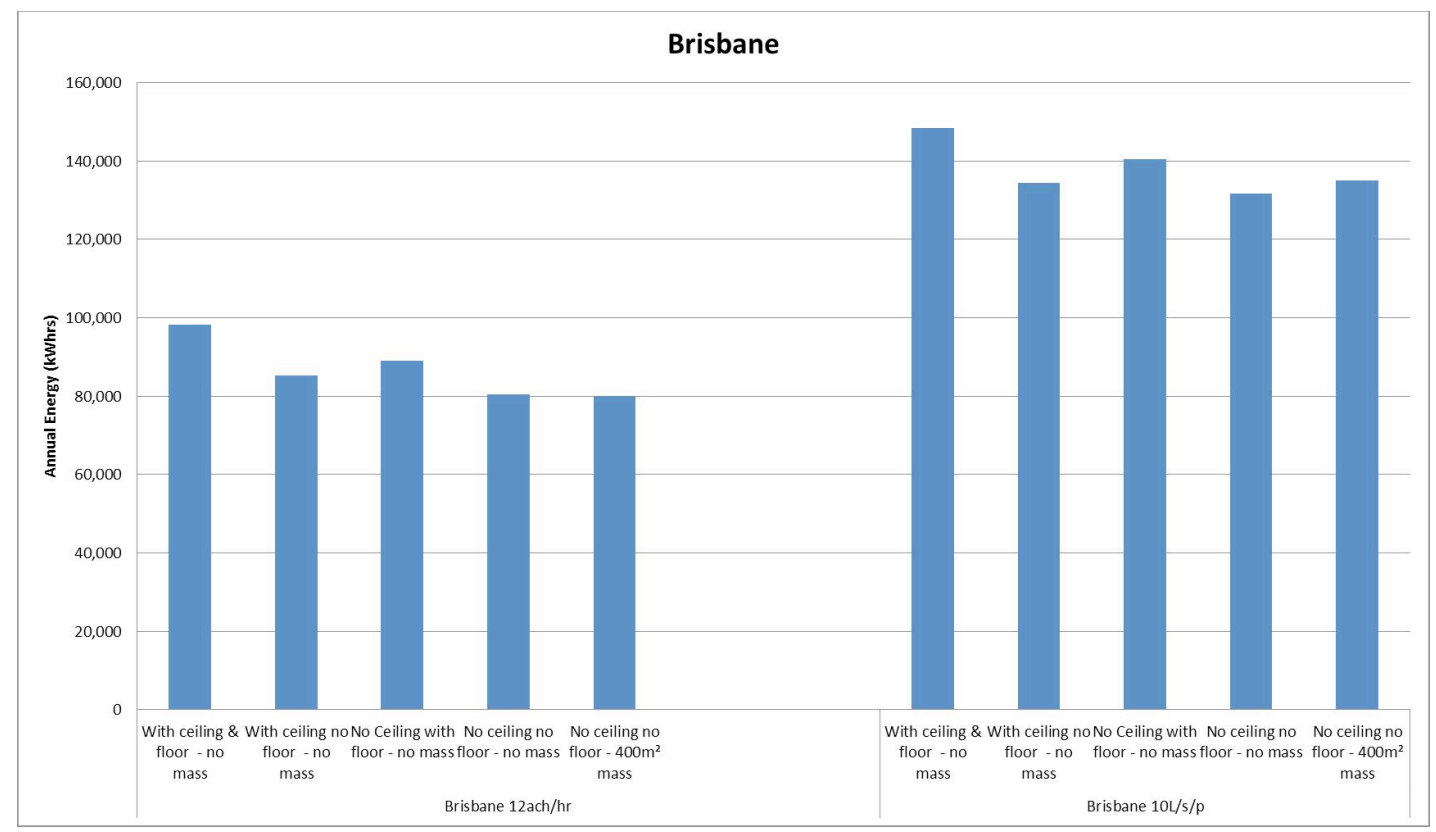

Figure 11: Effect of exposing internal thermal mass on annual energy use (Brisbane).

delivers energy savings in both the Adelaide and Brisbane climatic regions although the benefit is far less pronounced in Brisbane (Table 2).

Table 2: Energy Savings Achieved by Exposing Elements of Internal Mass with a Lightweight Façade Building

\begin{tabular}{|c|c|c|}
\hline \multirow{2}{*}{ Location } & Outside Air Rate & \% Energy Saving \\
\hline \hline \multirow{2}{*}{ Adelaide } & $12 \mathrm{ach} / \mathrm{hr}$ & $30 \%$ \\
\cline { 2 - 3 } & $10 \mathrm{~L} / \mathrm{s} / \mathrm{p}(21.2 \mathrm{cfm} / \mathrm{p})$ & $20 \%$ \\
\hline \multirow{2}{*}{ Brisbane } & $12 \mathrm{ach} / \mathrm{hr}$ & $19 \%$ \\
\cline { 2 - 3 } & $10 \mathrm{~L} / \mathrm{s} / \mathrm{p}(21.2 \mathrm{cfm} / \mathrm{p})$ & $11 \%$ \\
\hline
\end{tabular}

Whilst the effects of parasitic fan energy have not been included in this assessment, it is worth noting that fan energy is typically in the range of $1-2 \mathrm{~kW} / \mathrm{L} / \mathrm{s}$. An assessment on Adelaide's climate shows that an economy cycle system would operate for around 1,280 hours per annum and at the $10 \mathrm{~L} / \mathrm{s} / \mathrm{p}$ flow rate, this would equate to an additional 1,310kwh of energy or around $2 \%$ of the base lightweight façade case. The increase in fan energy for the VAV system is greater but the modulation of air flows possible reduces the impact and additional energy in the region of $5,000 \mathrm{kwh}$ is expected ( $15 \%$ of the base). This demonstrates that the additional fan energy is compensated for in cooling energy but a separate study is required to assess this in detail.
The reduction in peak demand for the centralised systems will enable the supply air flow rate for cooling to be reduced. This will assist in compensating for the increase in operating hours and annual fan energy.

\section{CONCLUSIONS}

It has been demonstrated that the exploitation of internal mass has a positive effect of between $30 \%$ and $16 \%$ for a building in a hot, dry climate such as Adelaide for centralised and decentralised systems, respectively. The savings achieved $18 \%$ to $10 \%$ for a building in a warm, humid climate such as Brisbane for centralised and decentralised systems, respectively. This is a very simple retrofit strategy to implement and whilst it has been demonstrated that increased air flows for decentralised systems to improve the benefit, it is not necessary to make savings.

Interestingly, for both centralised and decentralised systems a more positive impact is provided from exposing the floor rather than the ceiling for accessing additional thermal mass behind.

At low outside air volumes, the limits of the benefits gained from exposing thermal mass are seen when outside airflows fall below $30 \mathrm{~L} / \mathrm{s} / \mathrm{p}(63.6 \mathrm{cfm} / \mathrm{p})$. At flows below this level, thermal mass results in an increase in the annual cooling energy and also in required plant capacity. This is important to note when implementing an upgrade strategy to ensure an appropriate amount of thermal mass is exposed for the available flow rate. 
There is a positive impact in peak demand by exposing the thermal mass when an appropriate outside air flow rate is available. This can be very useful as part of a refurbishment strategy since primary air flows can be reduced.

The savings are similar in percentage for facades with optimum thermal mass (composite structures) as well as fully glazed facades with a conclusion that the strategy can be adopted for a wide range of building constructions and HVAC system types.

With decentralised systems which have little or no control over the outside air volume flow it has been demonstrated that the peak cooling load increases for a composite façade building and this is expected to be the case for the lightweight façade also. It is not proposed that increasing the outside air flow rate for decentralised systems be initiated without suitable controls in place to limit operation when ambient conditions are not favourable and this could be easily integrated as part of an upgrade strategy.

\section{REFERENCES}

[1] Artmann N, Manz $\mathrm{H}$ and Heiselberg P. Climatic potential for passive cooling of buildings by night-time ventilation in Europe. Applied Energy 2007; 84(2): 187-201. https://doi.org/10.1016/j.apenergy.2006.05.004

[2] Givoni B. Effectiveness of mass and night ventilation in lowering the indoor daytime temperatures. Energy and Buildings 1998; 28(1998): 25-32. https://doi.org/10.1016/S0378-7788(97)00056-X

[3] Shaviv E. Thermal mass and night ventilation as passive cooling design strategy. Renewable Energy 2001; 24(3-4): 445. https://doi.org/10.1016/S0960-1481(01)00027-1

[4] Koranteng $\mathrm{C}$ and Mahdavi A. An investigation into the thermal performance of office buildings in Ghana. Energy and Buildings $2011 ; 43(2-3)$ : 555-563. https://doi.org/10.1016/j.enbuild.2010.10.021

[5] Güçyeter B and Günaydın HM. Optimization of an envelope retrofit strategy for an existing office building. Energy and Buildings 2012; 55(0): 647-659. https://doi.org/10.1016/j.enbuild.2012.09.031

[6] Brown M. Optimization of thermal mass in commercial building applications. Journal of solar energy engineering
1990; 112: 273. https://doi.org/10.1115/1.2929934

[7] Zhou G, Krarti M and Henze G. Parametric analysis of active and passive building thermal storage utilization. Journal of solar energy engineering $2005 ; 127: 37$.

https://doi.org/10.1115/1.1824110

[8] Roach P, Bruno F and Belusko M. Modelling the cooling energy of night ventilation and economiser strategies on façade selection of commercial buildings. Energy and Buildings 2013; 66(0): 562-570. https://doi.org/10.1016/j.enbuild.2013.06.034

[9] Baldwin R, et al. BREEAM (Building Research Establishment Environmental Assessment Method) 98 for offices. Watford, UK, 1998.

[10] ABCB. Building Code of Australia (2007 edn). Canberra 2007.

[11] ABCB, Definition Of Basic Forms For Representative Buildings 1991: p. 5

[12] Kontoleon $\mathrm{K}$ and Bikas D. Modeling the influence of glazed openings percentage and type of glazing on the thermal zone behavior. Energy and Buildings 2002; 34(4): 389-399. https://doi.org/10.1016/S0378-7788(01)00125-6

[13] Kossecka $E$ and Kosny J. Equivalent wall as a dynamic model of a complex thermal structure. Journal of Building Physics 1997; 20(3): 249 https://doi.org/10.1177/109719639702000306

[14] Kossecka $E$ and Kosny J. Effect of insulation and mass distribution in exterior walls on dynamic thermal performance of whole buildings. Thermal performance of the exterior envelopes of buildings VII 1998: p. 721-731.

[15] Perez-Lombard L, Ortiz $\mathrm{J}$ and Maestre IR. The map of energy flow in HVAC systems. Applied Energy 2011; 88(12): 5020-5031.

https://doi.org/10.1016/j.apenergy.2011.07.003

[16] Nassif N. Performance analysis of supply and return fans for HVAC systems under different operating strategies of economizer dampers. Energy and Buildings 2010; 42(7): 1026-1037.

https://doi.org/10.1016/j.enbuild.2010.01.015

[17] Tsilingiris P. Parametric space distribution effects of wall heat capacity and thermal resistance on the dynamic thermal behavior of walls and structures. Energy and Buildings 2006; 38(10): 1200-1211. https://doi.org/10.1016/j.enbuild.2006.02.007

[18] Antonopoulos K. Envelope and indoor thermal capacitance of buildings. Applied Thermal Engineering 1999; 19(7): 743. https://doi.org/10.1016/S1359-4311(98)00080-5

[19] Al-Homoud M. Optimum thermal design of office buildings. International Journal of Energy Research 1998; 21(10): 941 957.

https://doi.org/10.1002/(SICI)1099-

114X(199708)21:10<941::AID-ER302>3.0.CO;2-Y

\section{DOI: http://dx.doi.org/10.15377/2409-9821.2017.04.02.1}

() 2017 Phillip Roach; Avanti Publishers.

This is an open access article licensed under the terms of the Creative Commons Attribution Non-Commercial License (http://creativecommons.org/licenses/by-nc/3.0/) which permits unrestricted, non-commercial use, distribution and reproduction in any medium, provided the work is properly cited. 